\title{
The uneven terrain of dialogical encounters and the spatial politics of listening
}

Dialogues in Human Geography 2018, Vol. 8(2) 160-167 (C) The Author(s) 2018 Reprints and permission: sagepub.co.uk/journalsPermissions.nav DOI: $10.1|77 / 20438206| 8780583$ journals.sagepub.com/home/dhg @SAGE

\section{Reuben Rose-Redwood}

University of Victoria, Canada

\section{Rob Kitchin}

National University of Ireland, Ireland

\section{Lauren Rickards \\ RMIT University, Australia}

\section{Ugo Rossi}

University of Turin, Italy

\section{Ayona Datta}

King's College London, UK

\section{Jeremy Crampton}

University of Kentucky, USA

\begin{abstract}
The contributions to this forum have highlighted how the limits to scholarly dialogue are multiple and have had serious consequences for the ways in which knowledges are produced and debated in the academy, the media, and wider society. In this rejoinder to the commentaries on our article, 'The Possibilities and Limits to Dialogue', we embrace the stance of affirmative critique in order to constructively engage with the important issues that our interlocutors raised. In particular, we consider questions of dialogical recognition, refusal, and the politics of listening as well as the need to strive not only to engage in dialogue but also to work toward changing the terms and terrain of dialogical engagement in order to produce a more equitable and just space of dialogical encounters in the academy.
\end{abstract}

\section{Keywords}

affirmative critique, dialogue, dialogical spaces, embodied action, politics of listening

\section{Corresponding author:}

Reuben Rose-Redwood, Department of Geography, University of Victoria, Victoria, BC V8N 3L2, Canada.

Email: redwood@uvic.ca 


\section{Introduction}

We would like to begin by thanking all of the commentators who have contributed their thoughtful and provocative reflections to this forum on the possibilities and limits to dialogue. Given our role as the editors of this journal, we are especially mindful of our own privileged positions in having the capacity to frame the 'terms and terrain' upon which this particular dialogical encounter has taken place. We also recognize that many voices are absent from the pages of this forum, including those who declined our invitations due to other commitments or concern over potential repercussions of sharing their own experiences and viewpoints, not to mention those who were not invited in the first place. We are under no illusions that the terrain of scholarly dialogue is a space equally accessible to all or a place in which 'rational minds' will eventually achieve a universal consensus through the disinterested search for 'truth', 'justice', or the 'good life'. On the contrary, dialogical encounters take place within an uneven terrain and are themselves implicated in constituting the conditions of possibility for the (re)production of dialogical spaces that amplify some voices while marginalizing others. As Sarah Wright notes in her commentary, dialogues 'not only take place in context, but also make that very context. For dialogue... sets norms as much as reflects them, makes and supports rules as much as follows them' (2018: 129). Dialogues in human geography, and within academia more broadly, are part of the performative enactment of scholarly norms, yet they also have the potential to open a space in which such norms may be contested, rearticulated, or refused. Indeed, it was an awareness of the potential for, and limitations to, dialogue that motivated our decision to write our initial article.

In our response to the commentaries, we seek to embrace the notion of affirmative critique proposed in this forum's anchor article in order to constructively engage with the important issues raised by the commentators that highlight the care with which questions of scholarly dialogue should be considered. By 'affirmative critique', we are not referring to 'the demand to be happy' or a requirement that scholarship must be 'oriented toward an enthusiastic or joyful disposition' (Cockayne and Ruez, 2018: 6). Indeed, affirmation and negativity need not be understood in oppositional terms, since what comes across as a 'negative' response to an unjust situation may itself be an affirmation of a particular conception of (in)justice. An affirmative stance toward critique, we suggest, would therefore benefit from considering the following question: 'What does any given critique seek to affirm and what are the possibilities and limits to dialogical engagement on those terms?' Framed in this way, affirmative critique is not reducible to the binary opposition between positivity and negativity. Rather, it underscores how dialogical encounters - as well as the refusal to accept the existing terms of debate-constitute the terrain within which new spaces of scholarly dialogue and praxis may emerge.

\section{'Beyond the comforts of good intentions': Dialogical recognition, refusal, and the politics of listening}

The possibility of dialogue and the exchange of ideas among scholars, and between scholars and wider publics, is a taken-for-granted assumption that underpins academic pursuits across the sciences and humanities. Yet Bruce Janz (2018) reminds us that while scholars have much to say, we often seem to have lost the capacity to listen, which poses a serious challenge to the very possibility of scholarly dialogue itself. He suggests that within the contemporary political climate of social polarization, dialogue all-too-often 'becomes a kind of game, a step on the way to war' where the primary objective is merely to 'score a goal and win for one's own side, which is already known to be the right and true side' (Janz, 2018: 125). While this may feel like a strategic necessity when political opponents are ready at hand to pounce on the slightest equivocation, it impoverishes the level of scholarly discourse, not only by reducing debate to well-worn lines but by eliminating the moment of listening. For, as compelling as an argument might be, if it is intentionally mischaracterized, caricatured, or simply ignored altogether-as often occurs to scholars from socially marginalized groups - then it becomes 
quite clear that listening (and the lack thereof) is a deeply political act.

Listening is a form of social and political recognition that is often conceived as a crucial condition for dialogical engagement. In practice, however, the very spaces in which scholarly dialogues occur are themselves part of institutional arrangements that privilege some forms of listening over others. For those who have historically been excluded from the arena of scholarly dialogue, one strategy of dialogical engagement is to seek greater recognition within the established fields of academic discourse. By contrast, another strategy is to reject the terms of dialogue and debate altogether, thereby employing the act of refusal as the basis for unsettling and reconfiguring the terrain of dialogue as a whole. As Sarah Wright (2018) observes, critical Indigenous scholarship has played a pivotal role in challenging the colonial logics that underpin the politics of recognition in both political and intellectual life (Coulthard, 2014; Simpson, 2014; in geography, see Daigle, 2016). In such works, the act of refusing to accept the existing conditions of dialogue can serve as 'a way of reframing debate, refocusing the terms of engagement, and re-centering it in productive ways' (Wright, 2018: 129). By rejecting the imperative to be recognized, and thus listened to, by the existing centers of power, dialogical refusal revalorizes the performative power of Indigenous selfaffirmation as a means of contesting the colonialist politics of subservient dependency associated with recognition-based modes of assessing scholarly value.

Indigenous critiques of colonial recognition are an important reminder that the space of dialogical engagement is not simply an arena of neutrality in which dialogue unfolds. It is established and maintained through a series of exclusions, and the act of inclusion can itself have the effect of reinforcing power asymmetries by solidifying and normalizing the unequal relations of political and intellectual authority between the 'recognizers' (those placed in an institutional position to recognize the Other) and the 'recognized' (those Others who are recognized by the gatekeepers of scholarly dialogue). It is therefore crucial, as Sanjay Srivastava (2018: 134) puts it, to move 'beyond the comforts of good intentions' evident in calls for 'global' dialogue and to instead consider the actually existing 'conditions of life' that constrain and enable the possibilities of scholarly dialogue across myriad axes of difference around the world. We could not agree more, which is why we have suggested that the limits to dialogue must be taken seriously rather than simply brushed aside as a minor inconvenience.

If a 'cosmopolitan' form of scholarly dialogue is possible at all, it must surely 'reject any homogenizing or universalizing impulses' and acknowledge the 'situatedness, diversity, and co-constitution of concepts and theories', as Junxi Qian contends (2018: 139). In retrospect, we can see how our own invitation to dialogue could certainly be read as universalizing the contemporary conditions of scholarly life in Anglophone academia to the world writ large, despite our efforts to avoid falling into precisely such a trap. By all means, the majorityworld need not 'accede to a system of political carbon-dating that is oriented to Anglo-American academia' (Srivastava, 2018: 134). Yet, as we noted in our anchor article, the turn toward right-wing ethno-nationalism and authoritarianism, and its impact on academic institutions, is not confined to Trump's America or Brexit UK but can also be found from Modi's India to Erdoğan's Turkey, and beyond.

We wrote our original piece in the immediate aftermath of the Unite the Right attacks in Charlottesville, Virginia, which is why we highlighted how that particular event served as a useful reminder of the ways in which academia is 'embroiled in the wider political currents of the day' (Rose-Redwood et al., 2018: 110). But the 'political currents of the day' are not universal conditions that shape scholarly life in a homogenous fashion globally; rather, both the 'currents' and the 'day' are spatially and temporally manifold. However, there are also points of intersection and connections across the multiplicity of worlds that we inhabit, which is why dialogue and other forms of embodied action have the potential to play an important role in enacting new spaces for 'the negotiation of relations within multiplicities' (Massey, 2005: 13). Srivastava (2018) questions whether dialogue is even possible across geographical divides, whereas Qian 
(2018: 141) suggests that scholarly dialogues can indeed 'emerge out of collisions between radically different socio-political contexts, intellectual traditions, ideological commitments, and styles of reasoning'. This leads him to support calls to 'bring Western and non-Western scholars together in the institutions and platforms of knowledge production and dissemination and translate this co-presence into meaningful talks and engagements' (Qian, 2018: 139). The main challenge, then, is to reconstitute academic 'institutions' and 'platforms' in such a manner that they do not systematically privilege Western scholarly traditions and claims to intellectual authority over all others from the very outset.

The decentering of Eurocentric structures of dialogue is easier said than done, given the extent to which 'whiteness' has long been viewed as a precondition for engaging in scholarly dialogue (Mott and Cockayne, 2018). As White supremacists, ethno-nationalists, and colonial apologists around the world have become increasingly emboldened in recent years, there has been a concerted effort to threaten, harass, and attempt to silence progressive scholars-especially feminists, anti-racist scholars, and postcolonial theorists - while simultaneously claiming victimhood under the banner of 'free speech' as a means of bolstering a racist and colonialist agenda within the academy (Cuevas, 2018; Kerr, 2018; Prashad, 2017). Increasingly, conservative media outlets such as Campus Reform and Turning Point USA have made it one of their primary missions to 'identify targets for harassment' and to encourage 'harassment campaigns against targeted professors' (Gallaher, 2018). Given the growing prevalence of such campaigns, as well as the pervasiveness of sexual harassment in academia, there is a growing recognition that harassment in all of its guises should be treated as a form of scholarly 'misconduct' (Marín-Spiotta, 2018).

In their commentary, Carrie Mott and Daniel Cockayne (2018) recount the harassment that they encountered in response to the publication of a journal article on the racialized and gendered politics of scholarly citation (Mott and Cockayne, 2017). Mott and Cockayne rightly maintain that 'harassment should not be counted as a foundation for thoughtful agonistic dialogue' (2018: 144), and they eventually chose to disengage from public discussions of their work after initial efforts resulted in an onslaught of targeted harassment. Under these circumstances, disengagement from public dialogue was a necessary form of selfcare, although the 'fear of further attention and harassment' had the unfortunate effect of foreclosing potentially 'legitimate opportunities for dialogue' (Mott and Cockayne, 2018: 145-146). Mott and Cockayne argue that certain forms of speech-i.e., hate speech, harassment, intimidation, and so forth - are not equivalent to democratic modes of speech, especially when they 'work against claims to democracy' itself (2018: 144; also, see Springer, 2018). Although hate speech is legally protected in some countries (e.g., the United States), this does not mean that certain platforms for dialogue-from social media to peer-reviewed scholarly journals - cannot establish their own ethical codes of conduct that bar discriminatory language and abusive behavior. In other words, individual scholars may have a legal right to promote hideous ideologies that call for the colonial subjugation of entire peoples, yet scholarly journals are not obliged to publish such works and journal editors have a responsibility to uphold both scholarly and ethical standards of academic research. Indeed, the publisher of this journal, SAGE, instructs its editors to 'maintain and promote consistent ethical policies for their journals'. Crucially, they go the next step to spell out that these policies are based upon ethical principles that 'promote fairness and equality and oppose discrimination' (SAGE Publishing, 2018). As the editors of Dialogues in Human Geography, we are committed to this goal, as no doubt many other journal editors in geography and other fields are as well.

\section{'Striving for something more radical than dialogue...'}

In the anchor article for this forum, we argued that scholarly dialogue is an embodied practice that cannot be disentangled from the power relations within which it is historically and geographically situated. This message is nothing new to feminist 
geographers and racialized minorities in the field of geography. As Camilla Hawthorne and Kaily Heitz observe, 'the historical exclusion of Black scholars and Black thought from human geography' has made Black geographers keenly aware of how the academy has long been 'a site for the reproduction of epistemic violence against women and people of color' (2018: 148). It is not enough, then, to simply offer Black geographers and other racialized minorities a 'seat at the table' while only paying 'lip service to Black scholarship' (Hawthorne and Heitz, 2018: 150). This form of exclusionary inclusion only serves to perpetuate the existing institutional structures of White power, so it is hardly surprising that Black geographers have often experienced a sense of alienation with the discipline during their graduate training and beyond.

Within this context, lauding the virtues of dialogue in an abstract sense, without accounting for the power imbalances that are embodied in the spaces of dialogical engagement, is clearly an inadequate response to the demands for equity and justice in the academy. If the latter are to be taken seriously, Hawthorne and Heitz argue that 'we should be striving for something more radical than dialogue' (2018: 150), where the goal of scholarly practice as embodied action is not simply to be included within existing dialogical spaces but rather to transform the very terrain of dialogical encounters themselves. These struggles are not merely 'intellectual exercises' alone, since 'they are tied to the urgency of our current conjuncture' (Hawthorne and Heitz, 2018: 151). Much work, then, needs to be done to reimagine, reconfigure, and decolonize geographical thought and praxis - including our own geographical imaginations, the spaces of work, disciplinary encounters, fieldwork, and public engagement-not simply to integrate diverse 'others' into existing centers of institutional power but rather to rethink the very notions of 'center' and 'margins' in academia. Such rethinking arguably requires experimentation of the sort that Bruce Braun (2015) advocates for as a more active yet humble alternative to conventional understandings of critique. However, as long as geography remains a predominantly white discipline (Pulido, 2002), all the theoretical experimentation in the world isn't going to address the important issues that Hawthorne and Heitz (2018), as well as other Black, Latinx, and Indigenous geographers, have raised.

Derek Alderman and Joshua Inwood (2018) contend that scholarly dialogue also has a significant role to play in shaping public discourse. Given the urgency of political action, they argue that the stakes are simply too high for scholars to disengage from consequential public debates. Taking their inspiration from Martin Luther King Jr's Letter from a Birmingham Jail (2013 [1963]), Alderman and Inwood maintain that calls for dialogue should not be an excuse for political inaction. For scholarly dialogue to have political purchase in wider public debates, it must therefore "not lose sight of the larger communities on the front lines of the struggle for survivability and freedom' (Alderman and Inwood, 2018: 153). This is an important observation, because the racist and sexist attacks that academics have endured in recent years are part of a much longer history of racial, gender, and class oppression. Scholarly dialogue has never been an autonomous realm of pure reflection and contemplation set apart from the power struggles of society. Indeed, academic institutions have historically played an instrumental role in legitimizing the status quo, yet they can also serve as spaces in which the injustices of the past and present are contested.

The key issue is not whether scholars should engage in, or disengage from, dialogue but rather: With whom should we engage in dialogue, on whose terms and terrain, and to what ends? Alderman and Inwood suggest that there is often little point in trying to engage in dialogue with extremists because "the broader challenge comes from those moderates in the middle who fail to appreciate or stand for justice in the face of obvious inequities [since]...they are the ones who allow oppressive structures to gain a foothold and thrive' (2018: 155). One problem that this argument encounters, however, is that the 'middle' is a shifting position that is anything but set in stone. What was once considered 'extreme' can come to be seen as the 'middle ground' if previously extreme positions are normalized. Defining what constitutes the 'center' - and drawing a line between the 'norm' and the 'extreme'-lies at the very heart of 
political life. Academic expertise is commonly enrolled in public debates as a political technology of truth-telling in order to legitimate a particular conception of the 'real' and the 'just' that necessitates a specific course of political action. In the absence of a transcendental foundation upon which to ground all ethical and political judgments, scholarly dialogue and political action alike 'will always be confronted with competing claims and forces' (Marchart, 2007: 3). Within such a postfoundational world, the 'impossibility of a final ground' need not imply a 'total absence of all grounds' but rather a recognition that the grounding of political action is necessarily contingent, provisional, and incomplete (Marchart, 2007: 2, italics in original).

In the heat of scholarly debate and political struggle, we often act as if our own epistemological, ontological, and ethical positions are firmly fixed on solid ground, which leads us to become entrenched in our own interpretive communities while rarely reaching out in a constructive manner to those who are perceived as the 'enemy'. Yet there are some occasions - rare as they may seem - when such dialogical encounters across the political divide can and do result in mutually beneficial interactions that have the potential to transform relations of 'enmity' into 'friendship'. Minelle Mahtani and Don Shafer's commentary presents us with one such dialogue between a mixed-race, female geographer of Muslim, Iranian-Indian descent turned radio show host and the CEO of a radio station who self-identifies as a White, US-born, Vietnam-war baby boomer from a 'dysfunctional Republican family' (2018: 157). They reflect upon how their initial hesitation eventually gave way to a mutual acknowledgment that 'it was possible to create collaborative knowledge' together, thereby breaking down some of the barriers that previously divided them (Mahtani and Shafer, 2018: 159). One of the most remarkable aspects of their dialogical encounters is that they both took a risk in agreeing to work with one another, when it would have been much easier to go their separate ways. When disagreements and tensions arose, they didn't give up but instead stuck it out to work through their differences, leading to positive changes for both of them.
While it would be hopelessly naive to assume that all disagreements and conflicts in scholarly and political life can be resolved in this dialogical manner, the mutual respect and support that Minelle and Don cultivated in their work relationship does offer some hope that affirmative critique can help create 'a space to challenge the friend/enemy distinction' in an increasingly polarized age (Mahtani and Shafer, 2018: 158-159).

\section{Conclusion}

Dialogical encounters - that is, the dialectics of speaking and listening as discursive and embodied acts - are often contrasted with real-world action, as if dialogue itself were not a form of embodied action-in-the-world. Yet speech and listening, as well as silence and ignoring, are all modes of bodily conduct that performatively enact social and political relations. Even in cases where dialogue is used as a strategy of inaction, delay, and deception, these political tactics are still forms of action, just as depoliticization is itself a deeply political act. Dialogue, after all, can be employed for many different ends, both to reaffirm and to contest the naturalized norms of social and political life. A critically affirmative politics of dialogue seeks to cultivate hope in the possibilities of dialogical encounters while also remaining mindful of the limits to dialogue.

As the contributions to this forum have highlighted, the limits to scholarly dialogue are multiple and have had serious consequences for the ways in which knowledges are produced-and reproduced - within academic institutions. For those whose voices have long been marginalized within scholarly discourse, calls for dialogue that emanate from the established centers of institutional power can be seen as a trap, especially if such dialogical exchanges are framed around a politics of recognition that solidifies the authority of the established power. Yet the very notion of dialogue can also be imagined otherwise by reshaping the terrain of dialogical encounters through a politics of selfdetermination rather than a politics of recognition (Eisenberg et al., 2014). For, as Frederick Douglass observed long ago, 
Power concedes nothing without a demand. It never did and it never will. Find out what any people will quietly submit to and you have found out the exact measure of injustice and wrong which will be imposed upon them, and these will continue till they are resisted with either words or blows, or with both. The limits of tyrants are prescribed by the endurance of those whom they oppress (1857: 22).

The spaces of scholarly dialogue are an important arena in which demands can be articulated and the limits of academic power and authority tested as a means of 'refocusing the terms of engagement' (Wright, 2018: 129). As right-wing academics and conservative commentators demand that tyrannical ideologies of colonial domination should be embraced as a legitimate form of academic discourse, scholars from socially marginalized and oppressed groups are no longer quietly submitting to such injustices and are instead rising up to demand that the terrain of scholarly dialogue be transformed into a more equitable and just space in which they too can thrive. Although the future of scholarly dialogue remains uncertain, one thing is clear: the uneven terrain of dialogical encounters is not fixed in place for all time, but is rather continuously in motion, which is why the spaces of scholarly dialogue are critical sites in the struggle over shaping what constitutes legitimate forms of scholarly knowledge and praxis.

\section{Declaration of Conflicting Interests}

The author(s) declared no potential conflicts of interest with respect to the research, authorship, and/or publication of this article.

\section{Funding}

The author(s) received no financial support for the research, authorship, and/or publication of this article.

\section{References}

Alderman D and Inwood J (2018) While we dialogue, others die: a response to 'The Possibilities and Limits to Dialogue'. Dialogues in Human Geography 8(2): 152-155.

Braun B (2015) From critique to experiment? Rethinking political ecology for the anthropocene. In: Perreault T,
Bridge G, and McCarthy J (eds), The Routledge Handbook of Political Ecology. London: Routledge, pp. 102-114.

Cockayne D and Ruez (2018) From affirmative to ambivalent critique: Difference, affect, and the politics of plurality. Unpublished manuscript.

Coulthard G (2014) Red Skin, White Masks: Rejecting the Colonial Politics of Recognition. Minneapolis: University of Minnesota Press.

Cuevas J (2018) A new reality? The far right's use of cyberharassment against academics. Academe, January-February. American Association of University Professors. Available at: https://www.aaup.org/article/ new-reality-far-rights-use-cyberharassment-againstacademics\#.WvTS7Mgh2uU (accessed 15 June 2018).

Daigle M (2016) Awawanenitakik: The spatial politics of recognition and relational geographies of Indigenous self-determination. The Canadian Geographer 60(2): 259-269.

Douglass F (1857) Two Speeches, by Frederick Douglass; One on West India Emancipation, Delivered at Canandaigua, Aug. 4th, and the Other on the Dred Scott Decision, Delivered in New York, on the Occasion of the Anniversary of the American Abolition Society, May, 1857. Rochester, NY: O.P. Dewey, Printer, American Office.

Eisenberg A, Webber J, Coulthard G, et al. (eds) (2014) Recognition Versus Self-Determination: Dilemmas of Emancipatory Politics. Vancouver: UBC Press.

Gallaher C (2018) War on the ivory tower: Alt right attacks on university professors. Political Research. Available at: http://feature.politicalresearch.org/waron-the-ivory-tower (accessed 15 June 2018).

Hawthorne C and Heitz K (2018) A seat at the table? Reflections on Black geographies and the limits of dialogue. Dialogues in Human Geography 8(2): 148-151.

Janz B (2018) Dialogue and listening. Dialogues in Human Geography 8(2): 124-127.

Kerr E (2018) White supremacists are targeting college campuses like never before. Chronicle of Higher Education, 1 February. Available at: https://www .chronicle.com/article/White-Supremacists-Are/ 242403 (accessed 1 February 2018).

King ML (2013 [1963]) Martin Luther King's Letter from a Birmingham jail. The Atlantic. Available at: https:// www.theatlantic.com/magazine/archive/2018/02/ letter-from-birmingham-jail/552461/ (accessed 15 June 2018). 
Mahtani M and Shafer D (2018) Dialogue, discourse, disjunctures: building critically affirmative politics in radio. Dialogues in Human Geography 8(2): 156-159.

Marchart O (2007) Post-Foundational Political Thought: Political Difference in Nancy, Lefort, Badiou and Laclau. Edinburgh: Edinburgh University Press.

Marín-Spiotta E (2018) Harassment should count as scientific misconduct. Nature 557: 141.

Massey D (2005) For Space. London: SAGE.

Mott C and Cockayne D (2017) Citation matters: Mobilizing the politics of citation toward a practice of 'conscientious engagement.' Gender, Place \& Culture 24(7): 954-973.

Mott C and Cockayne D (2018) Conscientious disengagement and whiteness as a condition of dialogue. Dialogues in Human Geography 8(2): 143-147.

Prashad V (2017) Academic argument backing white supremacy and colonialism are making an ominous comeback. Quartz, 22 September. Available at: https://qz.com/1083767/academic-argumentsbacking-white-supremacy-and-colonialism-aremaking-an-ominous-comeback/ (accessed 22 September 2017).
Pulido L (2002) Reflections on a white discipline. The Professional Geographer 54(1): 42-49.

Qian J (2018) The possibilities of cosmopolitan dialogue. Dialogues in Human Geography 8(2): 138-142.

Rose-Redwood R, Kitchin R, Rickards L, et al. (2018) The possibilities and limits to dialogue. Dialogues in Human Geography 8(2): 109-123.

SAGE Publishing (2018) Ethics \& responsibility. Available at: https://us.sagepub.com/en-us/nam/ethicsresponsibility (accessed 15 June 2018).

Simpson A (2014) Mohawk Interruptus: Political Life Across the Borders of Settler States. Durham, NC: Duke University Press.

Springer S (2018) Confronting hate speech with a geography of freedom. The Conversation. Available at: https://theconversation.com/anarchist-professortakes-on-hate-speech-93606 (accessed 21 March 2018).

Srivastava S (2018) On the merits of recognizing the near-impossibility of dialogue. Dialogues in Human Geography 8(2): 133-137.

Wright S (2018) When dialogue means refusal. Dialogues in Human Geography 8(2): 128-132. 